\title{
Psychological Restorative Potential of a Pilot on-Campus Ecological Wetland in Malaysia
}

\author{
Lai Kuan Lee ${ }^{1, *(\mathbb{D}}$, Nor Azazi Zakaria ${ }^{2}$ and Keng Yuen Foo ${ }^{2}$ (1) \\ 1 Food Technology Program, School of Industrial Technology, Universiti Sains Malaysia, \\ Gelugor 11800, Pulau Pinang, Malaysia \\ 2 River Engineering and Urban Drainage Research Center, Engineering Campus, Universiti Sains Malaysia, \\ Nibong Tebal 14300, Pulau Pinang, Malaysia; redac01@usm.my (N.A.Z.); k.y.foo@usm.my (K.Y.F.) \\ * Correspondence: 1.k.lee@usm.my; Tel.: +60-46536360
}

Citation: Lee, L.K.; Zakaria, N.A.; Foo, K.Y. Psychological Restorative Potential of a Pilot on-Campus Ecological Wetland in Malaysia. Sustainability 2022, 14, 246. https:// doi.org/10.3390/su14010246

Academic Editor: Alejandro Rescia

Received: 9 November 2021

Accepted: 22 December 2021

Published: 27 December 2021

Publisher's Note: MDPI stays neutral with regard to jurisdictional claims in published maps and institutional affiliations.

Copyright: (C) 2021 by the authors. Licensee MDPI, Basel, Switzerland. This article is an open access article distributed under the terms and conditions of the Creative Commons Attribution (CC BY) license (https:// creativecommons.org/licenses/by/ $4.0 /)$.

\begin{abstract}
This study examines the perceptions and engagement tendencies of 788 university students, as well as their relationship with psychological distress, with respect to an on-campus ecological wetland. The students' awareness, understanding, perceived importance, satisfaction level, and engagement tendency towards the ecological wetland were evaluated using a structured questionnaire. The psychological symptoms were assessed using the Rosenberg Self-Esteem and depression, anxiety, and stress scales, and the predictors of psychological distress were determined. The majority of the students were actively engaged $(62.3 \%)$, aware $(88.3 \%)$, and satisfied $(51.0 \%)$ with the ecological wetland. Gender, age, educational attainment, engagement, perceived importance, and satisfaction level towards the ecological wetland were the predictors of psychological distress. The results outlined the environmental and mental restorative values of the ecological wetland in mediating psychological distress among the university students. These findings shed light on the necessity of preserving the sustainability and integrity of the on-campus ecological wetland. Longitudinal investigations to explore the restorative values of built environments and psychological wellbeing among high-risk populations are warranted.
\end{abstract}

Keywords: restoration; built environment; wetland; students; psychological distress

\section{Introduction}

The psychological restorative effects of natural environments are dominated by two complementary but distinguishable theories. One emphasizes the recovery of the capacity to focus attention, while the other focuses on the reduction of psycho-physiological stress [1]. Accordingly, the attention restoration theory (ART) describes the role of natural environments in enhancing mental functioning through their unique capacity to govern attention, a cognitive resource that is specifically required for effective functioning in contemporary urban societies. It suggests that mental fatigue could be gradually corrected by time spent in-or exposure to-nature. Long-term engagement with natural settings would encourage more effortless brain function and allow the recovery or replenishment of directed attention capacity [2].

On the other hand, the stress recovery theory (SRT) describes the restoration from stress when an individual is confronted with a condition that is perceived as demanding or threatening to their wellbeing. This model was derived with the assumption that aesthetic responses to the visual stimuli of environmental settings would activate psycho-physiological responses and effective recovery from external stress from the perspective of cognitive restoration, physiological restoration, or affective restoration [3]. The joint effects of the environmental setting and the individual's preceding affective/cognitive/physiological state on adaptive responses could vary due to stress and avoidance of restoration and could affect behavior [4]. 
Although great experimental evidence has demonstrated strong restorative outcomes associated with natural scenes and settings, there are limited studies that have evaluated the relation between built environments and psychological status among university students [5]. The available research focused mainly on the influences of socio-demographic factors, social networks, and interpersonal problems that could be attributed to psychological distress [6,7]. Thus, it is worthwhile to examine the role of restorative environments (in this case, an on-campus ecological wetland) in mediating psychological distress among university students. In this sense, the present work was undertaken to provide a unique insight into university students' perceptions of and engagement with a 20-year-old on-campus ecological wetland in Malaysia. This study evaluated the students' self-rated perceptions (understanding and awareness, perceived importance, and satisfaction) and engagement tendencies towards the ecological wetland. The psychological status, including the depression, anxiety, stress, and self-esteem, among the university students was examined. The relationships between the students' perceptions, engagement tendencies, and psychological distress were explored, and the restorative potential of the ecological wetland was investigated. In this work, three hypotheses were examined. Hypotheses 1 and 2 were tested for the main effects, while Hypothesis 3 was tested for the modulation effects.

Hypothesis 1. The awareness, perceived importance, satisfaction level, and engagement tendencies with respect to the ecological wetland are satisfactory.

Hypothesis 2. The prevalence of psychological distress among university students is high.

Hypothesis 3. Socio-demographic profiles, engagement tendencies, and perceived importance are significant predictors for psychological distress, and a higher engagement tendency and perceived importance show a positive influence on the psychological status among the university students.

\section{Materials and Methods}

\subsection{Study Area}

This study was carried out within the engineering campus of Universiti Sains Malaysia (USM), which is populated by 3500 inhabitants. Located at the coordinates $5.1460^{\circ} \mathrm{N}$, $100.4929^{\circ} \mathrm{E}$ in the Nibong Tebal district, Penang Mainland, Malaysia, the campus is predominantly surrounded by palm oil plantation forests, rubber fields, animal husbandry, residential houses, a mosque, and farmlands. With a total area of $1.319 \mathrm{~km}^{2}$, the major layout includes academic buildings, student hostels, administration blocks, and sport centers.

A national pilot project for an ecological stormwater management system, which integrated the concept of best management practices (BMPs) for urban drainage based on the Urban Stormwater Management manual for Malaysia (MSMA), was adopted on the campus. This bio-ecological drainage system (BIOECODS) was constructed in December 2002 with the major objectives of promoting surface water infiltration and improving water quality on the campus. As an early attempt to overcome the three major environmental challenges in the country-water scarcity, river pollution, and flash floods-the main component of BIOECODS primarily comprises a bio-retention swale, dry, wet, detention, and recreational ponds, and an ecological wetland.

\subsection{Ecological Wetland}

The on-campus ecological wetland is located in the sub-catchment area of the engineering campus, with a catchment area of $1.214 \mathrm{~km}^{2}$. The original design concept for the ecological wetland was to create a natural environmental treatment system for water quality improvement. Various tropical wetland species were planted in different macrophyte zones. In the higher marsh areas, subsurface plants-notably, Eleocharis variegata, Eleocharis dulchis, and Hanguana malayana-were the dominant species, while Lepironia articulata, Typha augustifolia, and Phragmites karka (Figure 1) were cultivated in the lower marsh zones to improve stormwater runoff through their capability of providing oxygen 
and their tolerance for organic matter. This complex ecosystem also serves as a habitat for freshwater fish (Oreochromis niloticus, Colossoma macropomum, Channa micropletis, and Barbodes gonionotus) and bird species (Egretta intermedia, Alcedo atthis, Acridotheres tristis, and Haliastur indus). The ecological wetland is surrounded by a recreational pond, recreational amenities and facilities, flowery planting mixes, pedestrian and running paths, garden benches, and wooden booths.

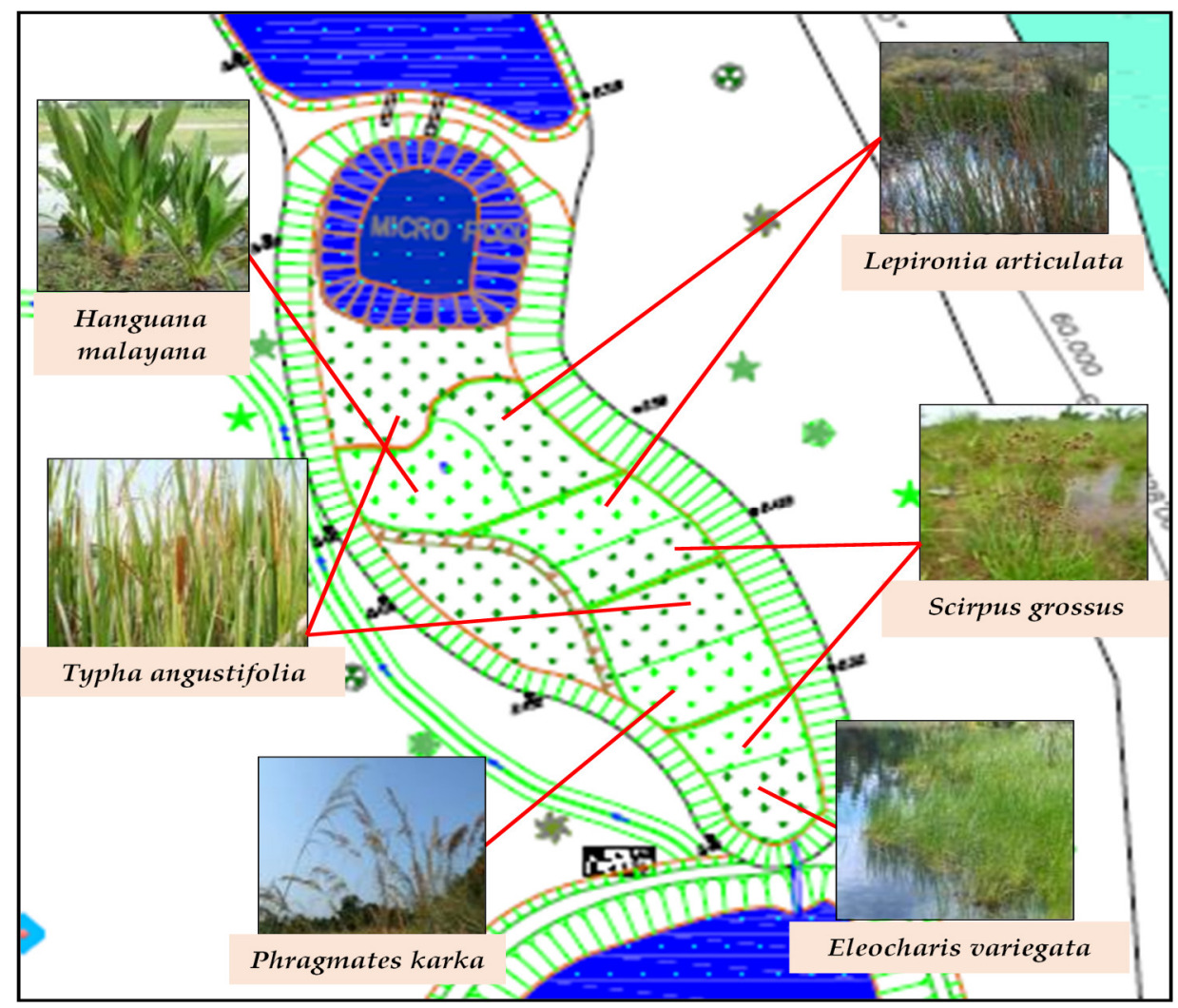

Figure 1. Schematic diagram of the ecological wetland on the engineering campus of Universiti Sains Malaysia. Various tropical wetland species were planted in different macrophyte zones. In the higher marsh areas, subsurface plants—notably, Eleocharis variegate, Eleocharis dulchis, and Hanguana malayana-were the dominant species, while Lepironia articulata, Typha augustifolia, and Phragmites karka were cultivated in the lower marsh zones to improve stormwater runoff through their capability of providing oxygen and their tolerance for organic matter.

\subsection{Participants and Sample Size Calculation}

Students (both undergraduate and postgraduate) from the engineering campus of USM were invited to participate in this study. The participation was voluntary and without monetary rewards, and students with documented psychiatric or/and mental disorders (self-report with medical record), such as schizophrenia, bipolar disorder, post-traumatic stress disorder, and eating disorders, were excluded from this study. The minimum sample size required for the significance level and degree of accuracy of $5 \%$ was derived as follows [8]:

$$
n=\frac{\chi^{2} N P(1-P)}{\Delta^{2}(N-1)+\chi^{2} P(1-P)}
$$

$n=$ Required sample size

$\chi^{2}=$ Confidence level of $95 \%$ (standard value of 3.84)

$N=$ Population size

$P=$ Estimated prevalence

$\Delta^{2}=$ Precision 
with $\chi^{2}=3.84, N=2638, P=0.7$, and $\Delta^{2}=0.05$. The participation of 720 university students was expected, with the assumption that the ratio of male to female students was 1 .

\subsection{Study Design}

The present work was designed as cross-sectional, semi-quantitative research that was aimed at clarifying university students' perceptions and experiences, which were distilled from their descriptions and served as evidence.

\subsection{Procedure}

Data sampling was conducted from March 2015 to September 2015 by trained project staff. Ethical approval for the research was sought from the Human Research Ethics Committee of Universiti Sains Malaysia (USM) prior to the commencement of the study (Code: USM/JEPeM/269.3(14). Convenience sampling was applied for the subject recruitment. Undergraduate and postgraduate students were approached in the lecture halls, student lounge, cafeteria, library, sport center, and hostels around the campus. They were briefed about the study, and those that agreed to participate gave their consent. Participants were provided with a printed booklet and a series of self-administered questionnaires (see Sections 2.6 and 2.7). The importance of the study, time commitment (30 min), and instructions for answering the questionnaires were highlighted. Participants were requested to submit the filled-out questionnaires to the research center on the same day, and any incomplete data were checked thoroughly.

\subsection{Questionnaire Design}

The self-administered questionnaire consisted of five major sections (Supplementary Materials S1, Part A):

(a) Demographics, living arrangements, lifestyle practices, and involvement in environmental institutions or organizations.

(b) The awareness and understanding of the ecological wetland, with five question items: (i) existence of the ecological wetland; (ii) role of the ecological wetland in managing stormwater flow; (iii) role of the ecological wetland in preventing and controlling flash floods; (iv) role of the ecological wetland in controlling water pollution; (v) the educational and research aspects of the ecological wetland. The participants rated the extent to which each item fit their feelings, thoughts, and behavior on a 5-point Likert scale.

(c) The tendency for engagement in the ecological wetland. The engagement features referred to activities that involved the ecological wetland. The frequency was defined (more than once per week, once per week, once per month, seldom, or never), and types of activities that were engaged (brisk walks, sightseeing, socializing, observing flora and bird species, picnics, research, and education) were evaluated.

(d) The perceived importance of the ecological wetland was justified in five major aspects: (i) functionality; (ii) environmental; (iii) sociological; (iv) health; (v) personal development, with higher ratings indicating a greater level of importance.

(e) Satisfaction with the constituent elements of the ecological wetland; this involved an evaluation of the functionality, physical environment, social environment, and health improvement. The degrees of satisfaction were defined as satisfied, neutral, or dissatisfied.

\subsection{Psychological Assessments}

2.7.1. Depression, Anxiety, and Stress Scale-42 (DASS-42)

The DASS-42 (42 items) (Supplementary Materials S1, Part B) is a self-administered scale for the reliable measurement of the negative emotional states of depression, anxiety, and stress, with fourteen items in each subscale [9]. It mainly assesses dysphoria, hopelessness, devaluation of life, self-deprecation, interest/involvement, anhedonia, and inertia, while the anxiety scale evaluates autonomic arousal, skeletal muscle, situational 
anxiety, and subjective experience of anxious affect. Meanwhile, the stress scale is specifically applied to examine the levels of chronic non-specific arousal in terms of difficulty in relaxation, nervous arousal, and being easily upset/agitated, irritable/over-reactive, and impatient. The participants rated the degree to which they experienced each state in the previous week by using a four-point severity/frequency scale, and the extent of severity was indicated by a standard severity rating index.

\subsubsection{Rosenberg Self-Esteem Scale (RSES)}

This self-administered scale consists of 10 statement items and is specifically applied to measure the overall self-esteem by using affirmations of both positive and negative statements [10]. The summed score was determined by the degree of self-esteem, with those who scored below 15 indicating a lower self-esteem (Supplementary Materials S1, Part B).

\subsection{Statistical Analysis}

Three types of data analysis were adopted. Firstly, descriptive statistics were used to analyze the demographic characteristics, awareness and understanding, engagement tendency, perceived importance, satisfaction level, and various psychological parameters. Secondly, categorical regressions were performed to identify the relative contributions of different factors to psychological distress. The descriptions of all of the independent variables of the regression model are shown in Supplementary Materials S2. The variance explained by $R^{2}$ was examined, in addition to the predictors of psychological distress in this model. Finally, the relationship of the engagement tendency and perceived importance (the independent variables) with the extent of psychological distress was examined through an analysis of variance (ANOVA) in a generalized linear model (GLM) with the use of Bonferroni adjustment for all pairwise comparisons. The statistical analysis was conducted using the SPSS version 17.0 software (SPSS, Chicago, IL, USA), with the significance defined as $p<0.05$.

\section{Results}

\subsection{Participants}

A total of 788 students (response rate $=84.9 \%$ ) participated in the study $(42.9 \%$ for men and $57.1 \%$ for women), with a mean age (SD) of $23.0 \pm 5.4$ years. The female students were older $(t=-3.07, p<0.01)$, and they showed lower odds of staying in the hostels $(O R=0.69, p<0.05)$. Meanwhile, the male students had a three-fold $(95 \% \mathrm{CI}=1.75-4.64)$ higher participation rate in environmental organizations (Table 1).

\subsection{Participants' Awareness and Understanding of the Ecological Wetland}

The participants considered themselves highly environmentally aware with the existence of this on-campus ecological wetland, with $88.9 \%$ and $87.6 \%$ levels of awareness among the male and female students, respectively. Similarly, $83.9 \%$ and $80.2 \%$ of the male and female students were familiar with the concept and operation of the ecological wetland, and the mean cumulative points for understanding were not statistically different. However, $18.0 \%$ of students were unaware of the distinct concept and functions of the ecological wetland. 
Table 1. Baseline characteristics of the participants.

\begin{tabular}{|c|c|c|c|c|c|}
\hline Characteristic & $n$ & Male $(n=338)$ & Female $(n=450)$ & OR $(95 \% \mathrm{CI})$ & $p$ \\
\hline \multicolumn{6}{|l|}{ Educational attainment } \\
\hline Undergraduate & 605 & $286(47.3)$ & $319(52.7)$ & \multirow{2}{*}{$2.26(1.58-3.23)$} & \multirow{2}{*}{$<0.0001^{* * *}$} \\
\hline Postgraduate & 183 & $52(28.4)$ & $131(71.6)$ & & \\
\hline \multicolumn{6}{|l|}{ Marital status } \\
\hline Single & 747 & $325(43.5)$ & $422(56.5)$ & \multirow{2}{*}{$1.66(0.85-3.25)$} & \multirow[b]{2}{*}{0.14} \\
\hline Married & 41 & $13(31.7)$ & $28(68.3)$ & & \\
\hline \multicolumn{6}{|l|}{ Living arrangements } \\
\hline Hostel & 578 & $234(40.5)$ & $344(59.5)$ & \multirow{2}{*}{$0.69(0.51-0.95)$} & \multirow{2}{*}{$0.02 *$} \\
\hline $\begin{array}{l}\text { Outside of campus } \\
\text { Involvement in } \\
\text { environmental } \\
\text { institutions }\end{array}$ & 210 & $104(49.5)$ & $106(50.5)$ & & \\
\hline Yes & 79 & $52(65.8)$ & $27(34.2)$ & \multirow{3}{*}{$2.85(1.75-4.64)$} & \multirow{2}{*}{$<0.0001^{* * *}$} \\
\hline No & 709 & $286(40.3)$ & $423(59.7)$ & & \\
\hline Age & 788 & $21.9 \pm 2.2$ & $22.5 \pm 2.8$ & & $0.003^{* *}$ \\
\hline
\end{tabular}

Student's $t$-test or $\chi^{2}$ test was used. Data are presented as numbers (\%) or means \pm S.D. * Significant at $p<0.05$, ** $p<0.01,{ }^{* * *} p<0.001$.

\subsection{Participants' Perceived Importance of and Satisfaction Level with the Ecological Wetland}

In descending order, the physical environment, health improvement, and stimulation of the social interactions were identified as the main factors of the perceived importance of the ecological wetland. Specifically, the majority of the students $(54.9 \%)$ perceived that the ecological wetland played a key role in improving the physical environment, enhancing the biodiversity of the flora and bird species (55.1\%), serving as a new habitat for wildlife $(41.2 \%)$, increasing the amenity values $(57.8 \%)$, and providing an aesthetic site for sightseeing $(65.4 \%)$. In a wider context, $44.5 \%$ of the participants perceived that the ecological wetland constituted an important asset of improvement to their health, whereas $51.7 \%, 43.2 \%$, and $38.5 \%$ of the students pointed out its feasibility for recreation and leisure, stress relief, and better quality of life, respectively. Additionally, $33.7 \%$ of the respondents enjoyed a wider social connection (32.5\%), moments of gathering $(38.7 \%)$, and conversation sessions $(29.8 \%)$ with their friends or family members, while only $9.0 \%$ of them ranked the ecological wetland as a unique tool for research development and educational purposes.

During the data entry, students who answered with satisfaction levels that were 'somewhat satisfied' and 'satisfied' were pooled and re-categorized as 'satisfied'. Similarly, those who gave ratings of 'somewhat dissatisfied' and 'dissatisfied' were merged and re-coded as 'dissatisfied', and the category of 'neither satisfied nor dissatisfied' was recoded as 'neutral'. The collected results revealed that $54.3 \%$ of the university students were satisfied with the ecological wetland, with one-third of them (34.2\%) rating it as neutral, while only $11.5 \%$ of them were dissatisfied with the current ecological wetland.

\subsection{Participants' Engagement Tendencies}

Figure 2 shows the students' tendencies for engagement with the ecological wetland according to gender. A total of $17.4 \%$ of the respondents visited the ecological wetland more than once a week, $44.9 \%$ and $24.0 \%$ of them visited once weekly and monthly, and $13.7 \%$ of them had never visited the wetland. The result implied that gender disparity was not significantly associated with the frequency of visiting. Observing wildlife, flora, and bird species $(n=105)$, socializing and gathering $(n=75)$, and sightseeing $(n=58)$ were the routine (at least once per week) activities for the male students, while more female students preferred to observe the wildlife, flora, and bird species $(n=128)$, socialize and gather $(n=101)$, and enjoy brisk walking $(n=74)$ during their visits. 
Brief visit/relaxing

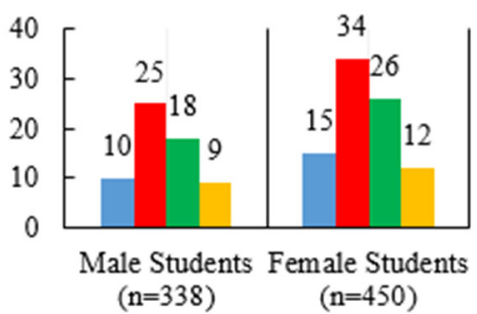

घ $>$ Once per week $\square$ Once per week

n Once per month ${ }^{-}$Seldom/Never
Brisk walk

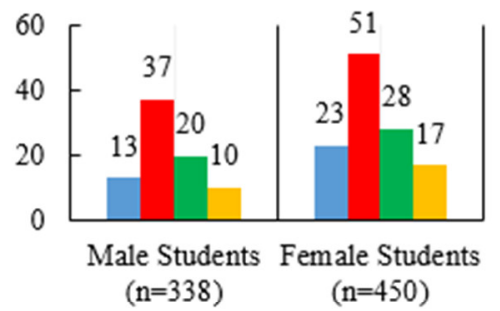

m> Once per week $\square$ Once per week

Once per month $n$ Seldom/Never
Running/Exercise

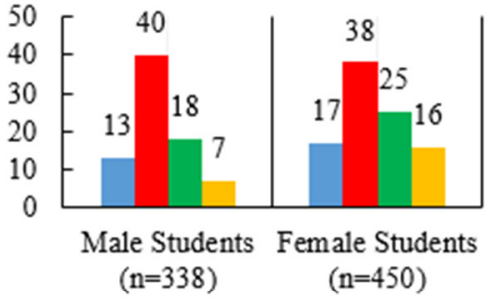

n> Once per week $\square$ Once per week

n Once per month $n$ Seldom/Never (a)

\section{Sightseeing}

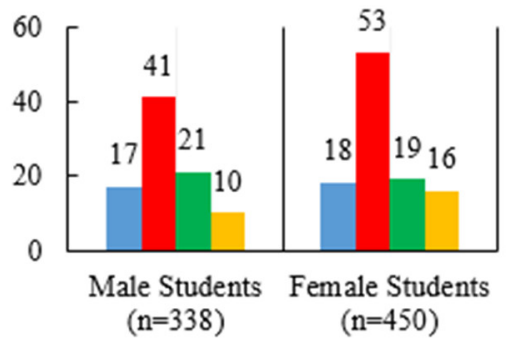

m > Once per week $\square$ Once per week

n Once per month $n$ Seldom/Never

(d)

\section{Observing wildlife, flora and bird species}

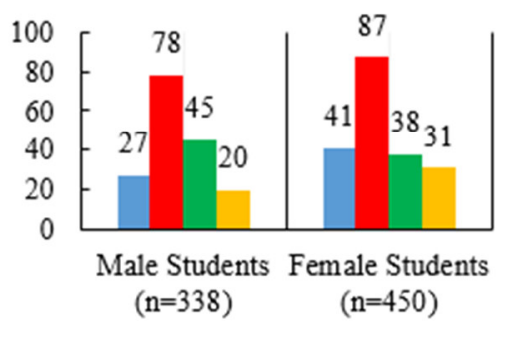

a > Once per week $\square$ Once per week

- Once per month Seldom/Never (b) (c)

\section{Socializing/Gathering/ \\ Conversation}

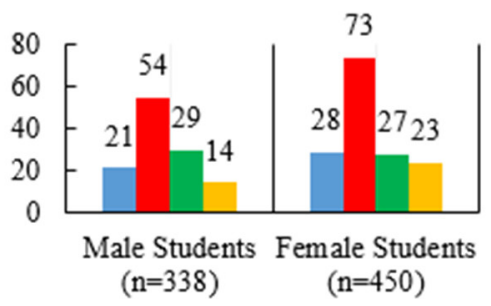

a $>$ Once per week $\square$ Once per week

ance per month $n$ Seldom/Never

(e)

\section{Research and education}

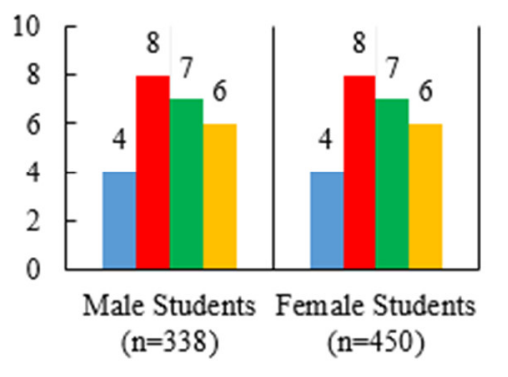

m> Once per week $\square$ Once per week

n Once per month $\|$ Seldom/Never

(g)

Figure 2. Engagement tendencies and participation in activities: (a) brief visits/relaxing; (b) brisk walk; (c) running/exercise; (d) sightseeing; (e) socializing/gathering/conversation; (f) observing wildlife, flora, and bird species; (g) research and education.

\subsection{Psychological Distress}

The prevalence of depression, anxiety, stress, and low self-esteem among the university students was $50.0 \%, 40.0 \%, 26.6 \%$, and $13.8 \%$, respectively. The female students had a higher likelihood of showing depressive symptomatology $\left(\chi^{2}=31.52 ;\right.$ OR $=2.271$; $95 \% \mathrm{CI}=1.702-3.030 ; p<0.0001)$ and stress $\left(\chi^{2}=3.87 ; O R=1.384 ; 95 \% \mathrm{CI}=1.000-1.914 ;\right.$ $p<0.05)$. However, the female students were confronted with a lower tendency $(43 \%)$ toward low self-esteem $\left(\chi^{2}=7.63 ; O R=0.566 ; 95 \% \mathrm{CI}=0.377-0.851 ; p<0.01\right)$. 


\subsection{Participants' Characteristics in Relation to Their Psychological Status}

The results of the regression model are presented in Table 2. Age revealed a significant negative sign for all three of the psychological distress indicators: depression $\left(R^{2}=0.035\right.$; $\beta=-0.187)$, anxiety $\left(R^{2}=0.013 ; \beta=-0.114\right)$, and stress $\left(R^{2}=0.246 ; \beta=-0.214\right)$. This finding implied that psychological distress was predominant among the younger students as compared to their older counterparts. In addition, being female was an important predictor for depressive symptomatology $\left(R^{2}=0.031 ; \beta=0.177\right)$, anxiety $\left(R^{2}=0.015\right.$; $\beta=0.123)$, and stress $\left(R^{2}=0.012 ; \beta=0.109\right)$ as compared with the male students. Similarly, education indicated a significant and positive sign for anxiety symptoms $\left(R^{2}=0.013\right.$; $\beta=0.114$ ), which suggested that higher educational levels presented higher degrees of anxiety symptomatology.

Table 2. Regression analysis with the degree of psychological distress related to demographics, engagement tendencies, perceived importance, and satisfaction.

\begin{tabular}{ccccc}
\hline Variables & Depression & Anxiety & Stress & Self-Esteem \\
\hline Female & $0.177(0.031)^{* * *}$ & $0.123(0.015)^{* * *}$ & $0.109(0.012)^{* *}$ & $-0.031(0.001)$ \\
Age & $-0.187(0.035)^{* * *}$ & $-0.114(0.013)^{* * *}$ & $-0.214(0.046)^{* * *}$ & $0.041(0.002)$ \\
Educational attainment & $0.042(0.002)^{* * *}$ & $0.114(0.013)^{* * *}$ & $0.068(0.005)$ & $-0.066(0.004)$ \\
Engagement tendency & $-0.505(0.459)^{* * *}$ & $-0.623(0.035)^{* * *}$ & $-1.084(0.050)^{* * *}$ & $1.618(0.002)^{* * *}$ \\
Perceived importance & $-0.668(0.447)^{* * *}$ & $-0.262(0.069)^{* * *}$ & $-0.430(0.185)^{* * *}$ & $0.290(0.084)^{* * *}$ \\
Satisfaction & $-0.089(0.008)^{* * *}$ & $-0.231(0.053)^{* * *}$ & $0.203(0.041)^{* * *}$ & $0.185(0.034)^{* * *}$ \\
\hline
\end{tabular}

Results are presented as standardized coefficients $\left(R^{2}\right){ }^{* *} p<0.01,{ }^{* * *} p<0.0001$.

\subsection{Engagement Tendency, Perceived Importance, and Satisfaction}

The engagement tendency, perceived importance, and satisfaction towards the ecological wetland were important predictors for depression, anxiety, and stress (negative signs) $(p<0.0001)$, as well as self-esteem (positive sign) $(p<0.0001)$, in the regression model. The strongest prediction was found between the extent of depression and engagement tendency $\left(R^{2}=0.459 ; \beta=-0.505\right)$, as well as perceived importance $\left(R^{2}=0.447 ; \beta=-0.668\right)$.

\subsection{Relationship of the Engagement Tendency and Perceived Importance with the} Psychological Symptoms

Significant and strong relationships were found between the engagement tendency and perceived importance and the psychological distress (Table 3). Students who visited the ecological wetland more frequently presented significantly lower scores for depression $(F=24.32 ; p<0.0001)$, anxiety $(F=21.93 ; p<0.0001)$, and stress $(F=24.25 ; p<0.0001)$. This result illustrated that university students with a higher tendency for engagement with the ecological wetland had relatively lower psychological distress. Similarly, the indicators of psychological distress $(F=222.542, p<0.0001$ for depression; $F=16.04, p<0.0001$ for anxiety; $F=50.55, p<0.0001$ for stress; $F=35.88, p<0.0001$ for self-esteem) decreased drastically among the university students who perceived the importance of the ecological wetland. These results firmly support the hypothesis that the psychological status among the university students would vary as a function of the engagement tendency and perceived importance with respect to the ecological wetland. 
Table 3. The associations of the engagement tendency and perceived importance with psychological distress.

\begin{tabular}{|c|c|c|c|c|c|c|}
\hline \multirow{2}{*}{$\begin{array}{l}\text { Psychological } \\
\text { Symptoms }\end{array}$} & \multirow[b]{2}{*}{ F Statistic } & \multicolumn{4}{|c|}{ Engagement Level } & \\
\hline & & Seldom/Never & $\begin{array}{l}\text { Once per } \\
\text { Month }\end{array}$ & Once per Week & $\begin{array}{l}\text { >Once per } \\
\text { Week }\end{array}$ & \\
\hline Depression & 24.32 & $11.3(10.4-12.2)^{\mathrm{a}}$ & $10.9(10.5-11.4)^{a}$ & $8.3(7.8-8.8)^{b}$ & $10.0(9.2-10.7)^{\mathrm{a}}$ & \\
\hline Anxiety & 21.93 & $5.7(5.1-6.3)^{\mathrm{a}}$ & $7.0(6.7-7.3)^{b}$ & $5.5(5.2-5.8)^{\mathrm{a}}$ & $5.0(4.5-5.5)^{\mathrm{a}}$ & \\
\hline Stress & 24.25 & $14.9(14.1-15.8)^{\mathrm{a}}$ & $12.4(11.9-12.8)^{b}$ & $10.8(10.4-11.3)^{b}$ & $11.8(11.0-12.5)^{b}$ & \\
\hline \multirow[t]{3}{*}{ Self-esteem } & 1.031 & $18.3(17.3-19.2)$ & $18.6(18.2-19.2)$ & 18.3 (17.7-18.7) & $17.9(17.0-18.7)$ & \\
\hline & & \multicolumn{5}{|c|}{ Perceived Importance } \\
\hline & F Statistic & $\begin{array}{c}\text { Not Important } \\
\text { at All }\end{array}$ & Less Important & Neutral & Important & Very Important \\
\hline Depression & 222.542 & $17.0(15.9-18.1)^{\mathrm{a}}$ & $12.5(11.7-13.3)^{b}$ & $12.0(11.7-12.3)^{b}$ & $6.3(5.9-6.6)^{\mathrm{c}}$ & $6.0(5.4-6.7)^{\mathrm{c}}$ \\
\hline Anxiety & 16.04 & $7.1(6.0-8.1)^{\mathrm{a}}$ & $7.0(6.3-7.8)^{a}$ & $6.5(6.2-6.8)^{\mathrm{a}}$ & $5.5(5.1-5.8)^{b}$ & $4.3(3.7-4.9)^{b}$ \\
\hline Stress & 50.55 & $17.0(15.6-18.4)^{\mathrm{a}}$ & $14.0(13.0-15.0)^{b}$ & $13.1(12.7-13.4)^{b}$ & $10.0(9.5-10.4)^{\mathrm{c}}$ & $9.6(8.8-10.4)^{c}$ \\
\hline Self-esteem & 35.88 & $15.3(13.8-16.9)^{\mathrm{a}}$ & $17.5(16.4-18.6)^{a}$ & $17.1(16.7-17.5)^{\mathrm{a}}$ & $20.8(20.3-21.3)^{b}$ & $18.9(18.0-19.8)^{\mathrm{c}}$ \\
\hline
\end{tabular}

Data are presented as means $(95 \%$ CI). Values in the same row that do not share the same superscript letter are significantly different.

\section{Discussion}

This was a pilot study examining university students' perceptions, engagement tendencies, and perceived importance with respect to an on-campus ecological wetland in Malaysia and their combinative associations with psychological symptoms. As such, this sample group represented a unique community character as compared to those in other population- and community-based studies. An initial finding of this work was the high level of awareness and degree of understanding of the wetland's concept. This result was not surprising given that the ecological wetland is a specific feature of the campus landscape.

Approximately $60 \%$ of the university students visited the ecological wetland at least once a week. It appeared that the university students expressed a preference for approaching environmental scenery, participation in social interactions, and practice of light exercise/training during their visits. This was applicable for those who appreciated, perceived the importance of, and were satisfied with the on-campus wetland. The results suggested the feasibility of the ecological wetland as a destination for mind relaxation and recreational or sport activities due to its existing physical environment and suggested an indirect value in engagement in human relationships. In parallel, the importance of the ecological wetland for promoting the physical and social environment, interpersonal interactions, and long-term improvement of health was highlighted [11]. Given the beneficial aspects of the ecological wetland, there are probable implications for the introduction of good monitoring strategies for the on-campus wetland, and an elucidation of the necessity of preserving the sustainability of its green assets has to be undertaken.

A number of instructive findings about the predictors of psychological distress in this study were noteworthy. The prevalence of psychological distress was apparently higher in the current study compared to in previous research conducted in Turkey (46.3\%) [12], Nigeria (8.3\%) [13], Iran (28.0\%) [14], and the United States (46.6\%) [15]. The variability of the findings among the listed studies could be attributed to differences in participants' backgrounds, the study design, types of psychological tests, operational diagnostic criteria, and geographical boundaries within the regions. Moreover, female students showed a higher tendency toward being affected by depression, anxiety, and stress. This result provided an insight into a gender-specific role in determining psychological health among the university students. Rivera-Medina and colleagues [16] proposed that a contribution from a difference in metric equivalence across gender resulted in the above findings. Age was another predictor of psychological distress, where psychological symptoms were more predominant among younger students. The study conducted by Bíró et al. [17] reported that the proportion of freshmen (younger) who suffered from psychological 
distress was almost three times greater than the proportion of final-year (older) students. The authors considered these younger students to be less mature, well prepared, or ready when confronted with different challenges. The present work also demonstrated that higher educational attainment was a significant predictor of anxiety, where postgraduate students would perceive a higher level of anxiety. This finding was contradictory with that of previous research carried out by Brännlund and Hammarström [18], which suggested that higher educational attainment was positively related to lower psychological distress. However, the role of educational attainment as a predictive factor has not been verified and is not conclusive, and further investigations are necessary.

Students who were satisfied with, more frequently visited, and appreciated the importance of the ecological wetland showed better psychological health. This on-campus wetland that was designed specifically for ecological reasons could serve as an important restorative environment by mediating mental health among the university students. It provides scenic fields with a waterside, wooded areas, bushes, rocks, built-up green spaces, and a variety of glorious plants for sightseeing. As such, students would appreciate the integration of greenery into the university environment [19]. Although the ultimate mechanism by which the ecological wetland facilitates a better psychological status is not fully understood, Abraham and coworkers [20] suggested that the role of the physical attributes of the natural environment and the types of activities in which people engage can influence the possibilities for psychological restoration [21]. Pretty and colleagues [22] also supported the synergistic effect of green exercise in significantly improving the self-esteem and mood among healthy adults, regardless of the level of intensity, duration, or type of green activities involved, while sightseeing was found to be advantageous for the enhancement of self-esteem. Therefore, the environmental stimuli provided by the on-campus ecological wetland could be a potential restorative tool for improving the psychological distress among the university students. Giusti and Samuelsson [23] suggested that synergistic compatibility between environmental attitudes and healthy ecosystems could trigger restorative processes. Such an interaction, which is known as generative compatibility, reveals a valuable leverage point for transforming towards ecologically sustainable and healthy urban systems.

Another finding of this work was the tendency for engagement through a series of social gatherings and activities on the ecological wetland. Staats and Hartig [24] demonstrated the encouraging impact of company on perceived psychological restoration in natural settings. This is particularly true because environmental engagement activities often involve improvements in social networking and feelings of connectivity and companionship [25]. These benefits could be important in solving internal conflicts and providing practical guidance and critical feedback in complex social situations [26]. This is because open communication and mutual engagement among peers could encourage internal emotional sharing and prevent psychological distress. Geng and colleagues [27] further ascertained the positive role played by connections with nature in promoting positive environmental behavior and in the development of pro-environmental behavior.

There were several strengths of this research. First, it was an early study that specifically investigated the relationship between university students' perceptions of and engagement with an on-campus ecological wetland and demonstrated the restorative effects of the built environment on psychological wellbeing, thereby bridging the research gap in the pool of currently available data. It also contributes to the existing knowledge by widening the literature on the potentially health-enhancing types of natural areas. Second, the results were acquired from a representative sample size, which yielded a higher reliability and allowed a direct extrapolation to the university students at large. The findings also outlined several implications for the community. The prevalence of psychological distress was found to be surprisingly high among the university students, which indicated a pressing need to further investigate the etiology and identify those at risk. The findings provided evidence that the presence of the ecological wetland ('hard') could serve as a mental health 
platform ('soft') for the university students, and improvement of the steps taken to preserve its sustainability should be empowered.

\section{Limitations}

Although a positive relationship between psychological restoration and the ecological wetland was found, the cross-sectional design did not show bidirectionality in these associations. The inherent bias in convenience sampling means that the sample is unlikely to be representative of the population being studied. Correlations between restorative environments, social relations, and mental health have been proposed; however, a deeper investigation that examines the interconnections between these parameters is recommended. In addition, there could be some other confounding and key factors affecting the results. For example, students with problems with psychological distress could be proactive in seeking assistance from health professionals. It is also possible that the degree of depression, anxiety, stress, and self-esteem among the university students could influence their interest in and engagement with the ecological wetland. The unmeasured covariates, such as the personality traits of the subjects, were not taken into account. Lastly, the current questionnaire has not been empirically validated. This innovation can be tested in a scholarly way by using a research method with an empirical survey for better interpretation of the data. Future research that involves a larger sample size and the integration of specific psychological evaluations would be a prominent strategy for further improving these findings.

\section{Conclusions}

Psychological distress is highly prevalent among university students, and the findings reinforced the compelling need for effective measures and preventive strategies. The majority of the students showed positive perceptions, engagement tendencies, and perceived importance with respect to the ecological wetland, and these were positively correlated with psychological symptoms. The findings revealed that the ecological wetland not only has potential for water quality improvement, biodiversity conservation, and stormwater storage, but also provides a natural psychologically restorative setting for its visitors. A longitudinal study that further explores the tendency for engagement with the ecological wetland and psychological wellbeing among university students is recommended. Ultimately, an integrated approach, which would require full participation and commitment from top management in involvement, should be systematically pursued to emphasize the psychological problems and to preserve the sustainability of the ecological wetland. Ultimately, the restorative benefits of nature exposure support people's wellbeing, and ecological sustainability is an urgent priority.

Supplementary Materials: The following supporting information can be downloaded at: https: / /www.mdpi.com/article/10.3390/su14010246/s1.

Author Contributions: All of the authors made substantial contributions to the conception and design of the experiment. Contributed in terms of conceptualization, acquisition and analysis of data, study design, and preparation of the article, L.K.L.; contributed in terms of resources, N.A.Z.; contributed in terms of conceptualization, methodology, and writing-review and editing, K.Y.F. All authors have read and agreed to the published version of the manuscript.

Funding: This research was funded by the Universiti Sains Malaysia under the Short-Term Grant Scheme [304/PTEKIND/61312127].

Institutional Review Board Statement: The study was conducted according to the guidelines of the Declaration of Helsinki, and approved by the Human Research Ethics Committee of Universiti Sains Malaysia (USM) (protocol code USM/JEPeM/269.3(14)).

Informed Consent Statement: Informed consent was obtained from all subjects involved in the study. Written informed consent has been obtained from the students to publish this paper.

Data Availability Statement: Data are available from the corresponding author on reasonable request.

Acknowledgments: The authors acknowledge the participation of all university students. 
Conflicts of Interest: The authors declare no conflict of interest.

\section{References}

1. Ulrich, R.S. Aesthetic and affective responses to natural environment. In Behavior and the Natural Environment, Human Behavior and Environment; Altman, I., Wohlwill, J.F., Eds.; Springer: Boston, MA, USA, 1983; pp. 85-125.

2. Hartig, T.; Mang, M.; Evans, G.W. Restorative effects of natural environment experiences. Environ. Behav. 1991, $23,3-26$. [CrossRef]

3. Parsons, R.; Tassinary, L.G.; Ulrich, R.S.; Hebl, M.R.; Grossman-Alexander, M. The view from the road: Implications for stress recovery and immunization. J. Environ. Psychol. 1998, 18, 113-139. [CrossRef]

4. Ibarra, R.P.; Tapia-Fonllem, C.; Fraijo-Sing, B.; Soto, N.N.; Poggio, L. Psychosocial Predispositions towards Sustainability and their Relationship with Environmental Identity. Sustainability 2020, 12, 7195. [CrossRef]

5. Aziz, F.; Md Rami, A.A.; Zaremohzzabieh, Z.; Ahrari, S. Effects of Emotions and Ethics on Pro-Environmental Behavior of University Employees: A Model Based on the Theory of Planned Behavior. Sustainability 2021, 13, 7062. [CrossRef]

6. Giannetti, B.F.; Velazquez, L.; Perkins, K.M.; Trillas-Ortiz, M.; Anaya-Eredias, C.; Agostinho, F.; Almeida, C.M.; Pinto, M.J.A.; Munguia, N. Individual-level characteristics of environmental sustainability among students in a higher education institution: The role of happiness and academic performance. Int. J. Sustain. High. Educ. 2021, 22, 1664-1690. [CrossRef]

7. Macharis, C.; Kerret, D. The 5E model of environmental engagement: Bringing sustainability change to higher education through positive psychology. Sustainability 2019, 11, 241. [CrossRef]

8. Krejcie, R.V.; Morgan, D.W. Determining sample size for research activities. Educ. Psychol. Meas. 1970, 30, 607-610. [CrossRef]

9. Lovibond, S.H.; Lovibond, P.F. The structure of negative emotional states: Comparison of the depression anxiety stress scales (DASS) with the beck depression and anxiety inventories. Behav. Res. Ther. 1995, 33, 335-343. [CrossRef]

10. Rosenberg, M. Society and the Adolescent Self-Image, 1st ed.; Princeton University Press: Princeton, NJ, USA, 1965.

11. De Young, R.; Scheuer, K.; Roush, J.; Kozeleski, K. Student interest in campus community gardens: Sowing the seeds for direct engagement with sustainability. In The Contribution of Social Sciences to Sustainable Development at Universities; Springer: Cham, Switzerland, 2016; pp. 161-175.

12. Bayram, N.; Bilgel, N. The prevalence and socio-demographic correlations of depression, anxiety and stress among a group of university students. Soc. Psychiatry Psychiatr. Epidemiol. 2008, 43, 667-672. [CrossRef] [PubMed]

13. Adewuya, A.O.; Ola, B.A.; Aloba, O.O.; Mapayi, B.M.; Oginni, O.O. Depression amongst Nigerian university students: Prevalence and sociodemographic correlates. Soc. Psychiatry Psychiatr. Epidemiol. 2006, 41, 674-678. [CrossRef] [PubMed]

14. Mousavi, S.G.; Keramatian, K.; Maracy, M.R.; Fouladi, M. Suicidal ideation, depression, and aggression among students of three universities of Isfahan, Iran. Iran. J. Psychiatry Behav. Sci. 2012, 6, 47-52. [PubMed]

15. Reyes-Rodríguez, M.L.; Rivera-Medina, C.L.; Cámara-Fuentes, L.; Suárez-Torres, A.; Bernal, G. Depression symptoms and stressful life events among college students in Puerto Rico. J. Affect. Disord. 2013, 145, 324-330. [CrossRef] [PubMed]

16. Rivera-Medina, C.L.; Caraballo, J.N.; Rodriguez-Cordero, E.R.; Bernal, G.; Davila-Marrero, E. Factor structure of the CES-D and measurement invariance across gender for low-income Puerto Ricans in a probability sample. J. Consult. Clin. Psychol. 2010, 78 , 398-408. [CrossRef] [PubMed]

17. Bíró, E.; Adány, R.; Kósa, K. Mental health and behaviour of students of public health and their correlation with social support: A cross-sectional study. BMC Public Health 2011, 11, 871. [CrossRef]

18. Brännlund, A.; Hammarström, A. Higher education and psychological distress: A 27-year prospective cohort study in Sweden. Scand. J. Public Health 2013, 42, 155-162. [CrossRef]

19. Van Den Bogerd, N.; Dijkstra, S.C.; Seidell, J.C.; Maas, J. Greenery in the university environment: Students' preferences and perceived restoration likelihood. PLoS ONE 2018, 13, e0192429. [CrossRef]

20. Abraham, A.; Sommerhalder, K.; Abel, T. Landscape and well-being: A scoping study on the health-promoting impact of outdoor environments. Int. J. Public Health 2010, 55, 59-69. [CrossRef]

21. Coon, J.T.; Boddy, K.; Stein, K.; Whear, R.; Barton, J.; Depledge, M.H. Does participating in physical activity in outdoor natural environments have a greater effect on physical and mental wellbeing than physical activity indoors? A systematic review. Environ. Sci. Technol. 2011, 45, 1761-1772. [CrossRef]

22. Pretty, J.; Peacock, J.; Sellens, J.; Griffin, M. The mental and physical health outcomes of green exercise. Int. J. Environ. Health Res. 2005, 15, 319-337. [CrossRef]

23. Giusti, M.; Samuelsson, K. The regenerative compatibility: A synergy between healthy ecosystems, environmental attitudes, and restorative experiences. PLOS ONE 2020, 15, e0227311.

24. Staats, H.; Hartig, T. Alone or with a friend: A social context for psychological restoration and environmental preferences. J. Environ. Psychol. 2004, 17, 283-300. [CrossRef]

25. Staats, H.; Jahncke, H.; Herzog, T.R.; Hartig, T. Urban Options for Psychological Restoration: Common Strategies in Everyday Situations. PLoS ONE 2016, 11, e0146213. [CrossRef] [PubMed]

26. Lee, $\mathrm{K}$. The role of media exposure, social exposure and biospheric value orientation in the environmental attitude-intentionbehavior model in adolescents. J. Environ. Psychol. 2011, 31, 301-308. [CrossRef]

27. Geng, L.; Xu, J.; Ye, L.; Zhou, W.; Zhou, K. Connections with Nature and Environmental Behaviors. PLoS ONE 2015, 10, e0127247. [CrossRef] [PubMed] 